\title{
Die Idolatrieanklage im Prozeß gegen Bonifaz VIII.*
}

Papstbildnisse gab es spätestens seit dem 4. Jahrhundert. Das älteste erhaltene Beispiel, eine ganzfigurige Darstellung von Papst Liberius (352-366), gehört, wie andere frühe Zeugnisse, dem Bereich der Katakombenmalerei an. Seither gab es in vielfältigen Formen und ikonographischen Zusammenhängen Papstbildnisse großen und kleinen Formats. ${ }^{1}$ Aber erst in der zweiten Hälfte des 13. Jahrhunderts kam es zur Verwendung skulpturaler Bildnistypen: Halbfigur, liegende Grabfigur, kniende Figur, Thronfigur und Standbild. Dieser mediale Innovationsschub hatte bereits begonnen, als Benedetto Caetani 1294 als Bonifaz VIII. (1294-1303) zum Papst gekrönt wurde. Dennoch gilt er weit mehr als seine unmittelbaren Vorgänger als Bahnbrecher skulpturaler Bildnisse, nicht nur aufgrund ikonographischer Neuerungen, mit denen er päpstliche Machtansprüche mit bisher nicht vorhandener Intensität bildlich propagierte, sondern bereits durch die spektakuläre Anzahl von acht großformatigen, skulpturalen Bildnissen, die innerhalb des nur neunjährigen Pontifikats entstanden (Abb.1). ${ }^{2}$

* Für eine kritische Lektüre des Textes danke ich Tatjana Bartsch und Ursula Rombach. Letztere übernahm freundlicherweise die Übersetzung der lateinischen Zitate. Auch hierfür sei ihr gedankt.

1 Rom, Praetextatus-Katakombe, Arkosolium der Celerina, siehe Gerhart B. Ladner: Die Papstbildnisse des Altertums und des Mittelalters, 3 Bde., Città del Vaticano 1941-1984, Bd. 1, 12-16.

2 Werner Hager: Die Ehrenstatuen der Päpste, Leipzig 1929, 10; Gerhart B. Ladner: Die Statue Bonifaz' VIII. in der Lateransbasilika und die Entstehung der dreifach gekrönten Tiara, in: Römische Quartalschrift für christliche Altertumskunde und Kirchengeschichte 42, 1934, 35-69; Harald Keller: Die Entstehung des Bildnisses am Ende des Hochmittelalters, in: Römisches Jahrbuch für Kunstgeschichte 3, 1939, 229-356, 283-284; Ladner 1970 (wie Anm. 1), Bd. 2, 285-340; Monika Butzek: Die kommunalen Repräsentationsstatuen der Päpste des 16. Jahrhunderts in Bologna, Perugia und Rom, Bad Honnef 1978, 59-73; Julian Gardner: Boniface VIII as a Patron of Sculpture, in: Roma anno 1300. Atti della IV settimana di studi di storia dell'arte medievale, Roma 19-24 maggio 1980, Roma 1983, 513-522; Nancy Nash: Boniface VIII and Honorific Portraiture. Observations on the Half-Length Image in the Vatican, in: Gesta 36/1, 1987, 47-58; Agostino Paravicini Bagliani: Le chiavi e la tiara. 
Die Tatsache, daß in dem Prozeß, den der französische König Philipp der Schöne gegen den Papst initiierte, auch dessen Statuen (imagines, statuae) als Belege für den Vorwurf der Idolatrie zur Sprache kommen sollten, hat zudem Anlaß gegeben, einen gleichsam epochalen Konflikt zwischen mittelalterlicher und bereits neuzeitlicher Einstellung zur Bildniskunst zu diagnostizieren. ${ }^{3}$

Das erste Bildnis von Bonifaz VIII. ist bereits für die Zeit vor seinem Pontifikat bezeugt. 1290 wurde Benedetto Caetani als Kardinaldiakon zusammen mit dem Kardinalbischof Gerardo Bianchi nach Frankreich entsandt, um in Reims einen langjährigen Streit zwischen dem dortigen Erzbischof und dem Domkapitel zu beenden. Dem bald erzielten Schlichtungsspruch wurde eine Verfügung angeschlossen, durch die beide Legaten die Konfliktparteien verpflichteten, ihnen zwei Silberstatuetten anfertigen zu lassen. Diese sollten als Kardinaldiakon bzw. Kardinalbischof gekennzeichnet sein und die Namensinschriften der Schlichter tragen. Die Verwendung der Bildnisse wurde genau geregelt. Sie wurden dazu bestimmt, bei feierlichen Gottesdiensten auf dem Hauptaltar zu stehen und die Anwesenden an die getroffenen Vereinbarungen zu erinnern. In der Verfügung findet sich die Verewigungsformel ,ad perpetuam rei memoriam“.4

Elf Jahre später traf Benedetto Caetani, inzwischen Papst Bonifaz VIII., eine ähnliche Entscheidung, als er einen anderen Konflikt zwischen dem Bischof von Amiens, Guillaume de Macon, und dem Kapitel des Doms zu schlichten hatte. In diesem Fall mußten die Konfliktparteien eine Madonnenfigur und ein Bildnis des Papstes anfertigen lassen, dieses Mal aus vergoldetem Silber. Auch diese Statuetten sollten bei feierlichen Gottesdiensten „ad perpetuam rei memoriam" auf dem Hauptaltar zu sehen sein. ${ }^{5}$

Immaginie simboli del papato medievale, Rom 1998, 18, 20-21, 33-34, 50, 69-76, 78, 92-93; Kat. Anno 1300 il primo Giubileo. Bonifacio VIII e il suo tempo, hrsg. v. Marina Righetti Tosti-Croce, Rom, Museo Palazzo Venezia, Mailand 2000, 133-136, Nr. 70-73 (Anna Maria D'Achille, Tommaso Strinati, Saverio Urciuoli); Agostino Paravicini Bagliani: Bonifacio VIII, Turin 2003, 109-115, 223-235, 282-283, 333-338; Valentino Pace: Una presenza marginale. L'immagine di Bonifacio VIII e i programmi figurativi moderni nella Roma trionfante del primo giubileo, in: Bonifacio VIII. Atti del XXXIX Convegno storico internazionale, Todi, 13-16 ottobre 2002 (Centro italiano di studi sul Basso Medioevo - Accademia Tudertina / Centro di studi sulla spiritualità medievale dell'Università degli Studi di Perugia), Spoleto 2003, 501-520; Agostino Paravicini Bagliani: Cultura e mentalità di Bonifacio VIII. A proposito di alcuni studi recenti, in: Bonifacio VIII, i Caetani e la storia del Lazio, Atti del Convegno di studi storici, Roma, Latina, Sermoneta, 30 novembre - 2 dicembre 2000, Rom 2004, $23-41$, bes. $30-35$.

3 Clemens Sommer: Die Anklage der Idolatrie gegen Papst Bonifaz VIII. und seine Porträtstatuen, Freiburg im Breisgau 1920, 26.

4 Tilmann Schmidt: Papst Bonifaz VIII. und die Idolatrie, in: Quellen und Forschungen aus italienischen Archiven und Bibliotheken 66, 1986, 75-107, 82-93; vgl. auch Sommer 1920 (wie Anm. 3), 21-23, 35-36; Butzek 1978 (wie Anm. 2), 60-63; Paravicini Bagliani 2003 (wie Anm. 2), 34-35, 282.

5 Schmidt 1986 (wie Anm. 4), 93-107. 
Die Idolatrieanklage im Prozeß gegen Bonifaz VIII.

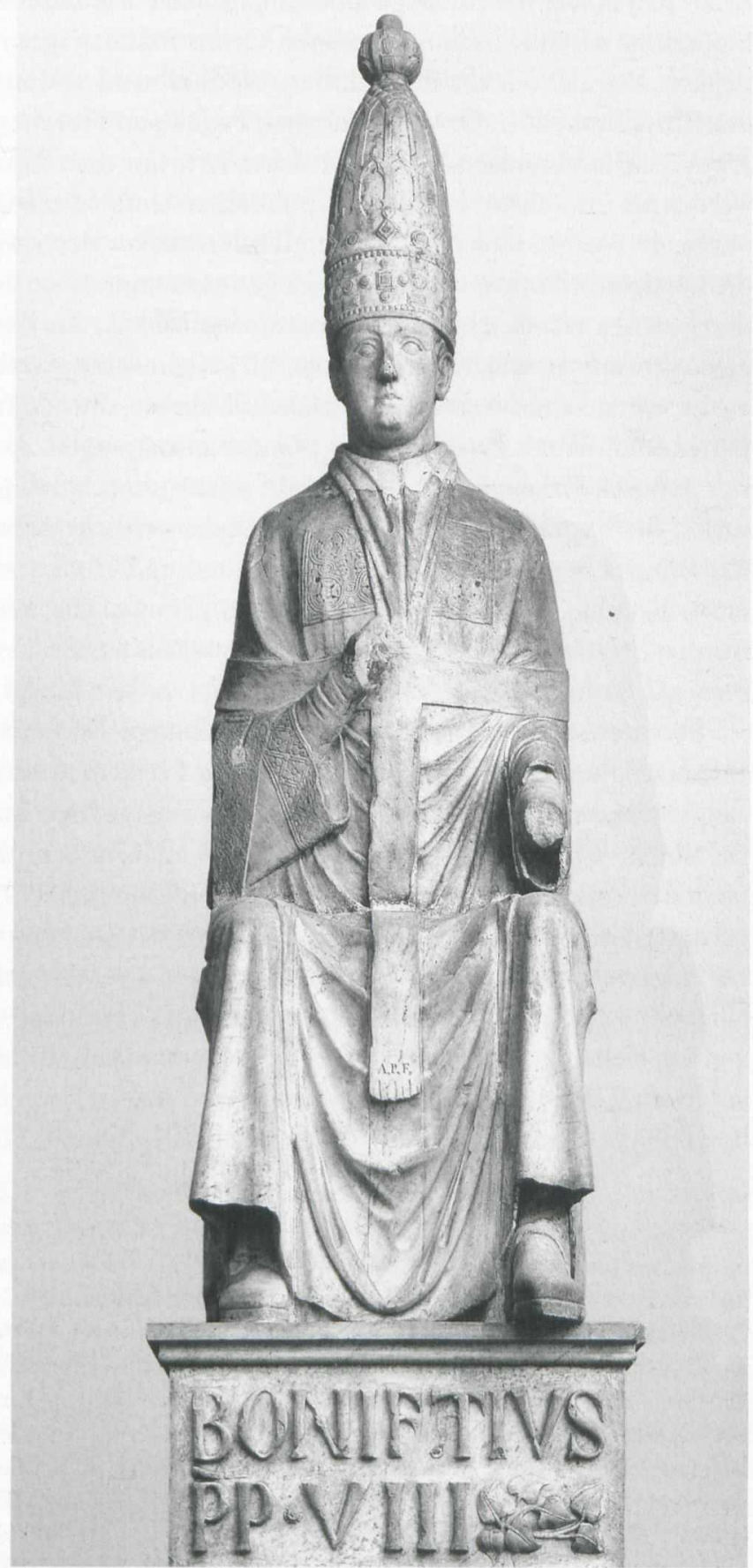

Abb. 1: Arnolfo di Cambio, Papst Bonifaz VIII., 1296-1302 (?), von der ehemaligen Domfassade, Florenz, Museo dell'Opera del Duomo 
In Italien war die Sachlage eine andere. Hier wurden für Bonifaz in einigen Städten an kirchlichen und profanen Orten Bildnisstatuen errichtet bzw. nur geplant, die nicht durch ihn selbst angeordnet worden waren. Es handelte sich um Ehrenstatuen. In Orvieto, Bologna, Padua und Florenz wurden sie von den jeweiligen kommunalen Gremien dekretiert, um den Papst wegen konkreter Verdienste (gewährter Privilegien, politischer Unterstützung usw.) dauerhaft zu ehren. In Anagni und in Rom könnten Kanoniker der jeweiligen Kirchen für die dortigen Bildnisse verantwortlich gewesen sein, da sie durch Bonifaz gefördert worden waren. Das einzige marmorne Bildnis, das dieser nachweislich in eigenem Auftrag schaffen ließ, ist die Liegefigur seines Grabmals. ${ }^{6}$

Es waren keineswegs die zahlreichen Bildnisse, die den französischen König motivierten, einen Prozeß gegen Bonifaz anzustrengen. Ausschlaggebend waren politische Machtfragen. ${ }^{7}$ Aufgrund seiner unnachgiebigen, intensiven Versuche, die Suprematie des Papsttums gegen weltliche Mächte durchzusetzen, war Bonifaz bereits 1296 durch ein Besteuerungsverbot des Klerus in einen offenen Konflikt mit Philipp dem Schönen geraten. Die Auseinandersetzungen wurden beigelegt, spitzten sich aber 1301 wieder zu, als dieser den Bischof von Pamiers, Bernard Saisset, wegen Hochverrats vor sein königliches Gericht zitierte. Bonifaz intervenierte mit Gegenmaßnahmen. Er forderte die Freilassung Saissets, entzog dem König alle päpstlichen Privilegien, wodurch das Besteuerungsverbot wieder erneuert wurde, und lud ihn und den französischen Episkopat für Ende 1302 zu einer Synode nach Rom. Um dem drohenden Kirchenbann des Papstes zu entgehen, unternahm Philipp der Schöne 1303 angesichts geringer Verhandlungschancen den Versuch, dessen Absetzung zu erzwingen. Da aufgrund des rechtlichen Grundsatzes „Papa a nemine iudicandus, nisi deprehendatur a fide devius ${ }^{\text {“8 }}$ ein Papstprozeß nur als Häresieprozeß geführt werden konnte, zielte das Anklagematerial vor allem darauf ab, Bonifaz als Häretiker zu verurteilen. Man warf ihm aber auch diverse andere Vergehen vor (alia diversa horribilia et detestabilia crimina ${ }^{9}$ ), vor allem Illegitimität, Simonie, Idolatrie so-

6 Jörg Garms /Andrea Sommerlechner/Werner Telesko (Hrsg.): Die mittelalterlichen Grabmäler in Rom und in Latium vom 13. bis zum 15. Jahrhundert, Bd. 2: Die Monumentalgräber, Wien 1994, 136-145, Nr. 44.

$7 \mathrm{Zu}$ den politischen Hintergründen des Prozesses siehe Tilmann Schmidt: Der BonifazProzess. Verfahren der Papstanklage in der Zeit Bonifaz' VIII. und Clemens' V (Forschungen zur kirchlichen Rechtsgeschichte und zum Kirchenrecht 19), Köln/Wien 1989 ; Jean Coste: Boniface VIII en procès. Articles d'Accusation et déposition de témoins (1303-1311) (Studi e documenti d'Archivio 5), Roma 1995; vgl. auch Jeffrey H. Denton: Taxation and the Conflict between Philip the Fair and Boniface VIII., in: French History 11, 1997, 241-264; Alessandro Barbero: Bonifacio VIII e la casa di Francia, in: Bonifacio VIII. Atti del XXXIX Convegno 2003 (wie Anm. 2), 273-327; Paravicini Bagliani 2003, 279-372.

8 Schmidt 1989 (wie Anm. 7), 1.

9 Coste 1995 (wie Anm. 7), 141. 
wie Sodomie. ${ }^{10}$ Die Idolatrie-Anklagepunkte gehörten zum Häresiekomplex. Sie betrafen nicht nur den idolatrischen Gebrauch von Bildnissen, sondern auch Dämonenverehrung. Der Tod des Papstes, am 11. Oktober 1303, drei Wochen nach seiner vorübergehenden Gefangennahme in Anagni, ${ }^{11}$ verhinderte eine rasche Durchführung des Prozesses. Die folgenden Päpste Benedikt XI. (1303-1304) und Clemens V. (1305-1314) korrigierten die antifranzösische Politik des Bonifaz, verzögerten jedoch die Weiterverfolgung der gegen ihn erhobenen Häresieanklage, da negative Konsequenzen für das Papsttum zu befürchten waren. ${ }^{12}$ Erst sechs Jahre später, im Frühjahr 1310, bemühte man sich, die offene Frage des Bonifazprozesses zu regeln. In mehreren Verhandlungsrunden wurden verfahrensrechtliche Probleme, aber auch Anklagematerialien vor Clemens V. und seinen Kardinälen in Avignon erörtert. Die Bildnisstatuen des Bonifaz kamen damals jedoch nicht mehr zur Sprache. Man befaßte sich lediglich mit den Vorwürfen idolatrischer Dämonenverehrung. Im April 1311 einigte man sich dann darauf, den Prozeß in ein Offizialverfahren ohne Beteiligung von Opponenten und Defensoren umzuwandeln. ${ }^{13}$ Ein Urteil kam nicht zustande, da Zeugenaussagen ausblieben..$^{14}$ Die damnatio memoriae Bonifaz VIII. fand nicht statt.

Die im Verlauf der Prozeßvorbereitungen formulierten Idolatrie-Vorwürfe sind in drei Fassungen überliefert. Die erste ist in der Rede enthalten, die einer der königlichen Ritter (miles regis), Guillaume de Plaisians, als offizieller Ankläger vor dem französischen König und einer Versammlung hochrangiger Adeliger und Prälaten am 14. Juni 1303 hielt. ${ }^{15}$ Diese Fassung lautet: „Ebenso ließ er, um sein allerverdammungswürdigstes Andenken zu verewigen, silberne Bildnisse von sich in Kirchen aufstellen und verführte dadurch die Menschen zur Idolatrie. ${ }^{\text {"16 }}$ Angesprochen waren jene Memorialstatuetten aus Silber bzw. vergoldetem Silber, die in Reims und Amiens auf Anordnung von Bonifaz VIII. anläßlich juristischer Streitfälle angefertigt worden waren.

10 Coste 1995, 73-122 (zu Guillaume de Nogarets am 12. März 1303 vor dem französischen König und seinen Ratgebern gehaltenen Rede), 122-173 (zur Anklageschrift des Guillaume de Plaisians); vgl. Schmidt 1989 (wie Anm. 7), 54-87.

11 Kaspar Elm: Das Attentat von Anagni. Der Überfall auf Papst Bonifaz VIII. am 7. September 1303, in: Alexander Demandt (Hrsg.), Das Attentat in der Geschichte, Köln 1996, 91-106; Paravicini Bagliani 2003 (wie Anm. 2), 347-366.

12 Schmidt 1989 (wie Anm. 7), 144; Elm 1996 (wie Anm. 11), 100-101.

13 Coste 1995 (wie Anm. 7), 753-761; Schmidt 1989 (wie Anm. 7), 374-386, bes. 386 und 394-426.

14 Coste 1995 (wie Anm. 7), 761-766; Schmidt 1989 (wie Anm. 7), 197-247, 432.

15 Schmidt 1989 (wie Anm. 7), 69-74; Coste 1995 (wie Anm. 7), 122 -173; Paravicini Bagliani 2003 (wie Anm. 2), 320-342, bes. 333.

16 Coste 1995 (wie Anm. 7), 148 (B16): „Item ut suam damnatissimam memoriam perpetuam constituat, fecit imagines suas argenteas erigi in ecclesiis, per hoc homines ad ydolatrandum inducens." 
In der zweiten Version der Anklage, die zwischen 1303 und 1307 von Kardinal Pietro Colonna verfaßt wurde ${ }^{17}$, ist der Vorwurf der Idolatrieanstiftung nicht auf die in Kirchen aufgestellten imagines argenteae beschränkt, sondern er wird auf die in mehreren italienischen Städten aufgestellten Marmorstatuen des Papstes ausgedehnt: Zudem wird behauptet, Bonifaz habe beabsichtigt, einen Bildkult zur Verherrlichung des jeweils amtierenden Papstes zu etablieren:

„[43] Achter Artikel. Ebenso ließ er, um sein allerverdammungswürdigstes Andenken zu verewigen, silberne Bildnisse von sich in Kirchen aufstellen und verführte dadurch die Menschen zur Idolatrie.

[44] Die Wahrhaftigkeit dieses Artikel wird durch Augenzeugenschaft bewiesen werden.

[45] Ebenso wird klar bewiesen werden, daß er nicht nur in Kirchen, sondern auch außerhalb der Kirchen, an und über den Stadttoren seine marmornen Statuen aufstellen ließ, wo von altersher Idole ihren Platz zu haben pflegten, was noch mehr den Verdacht schürt, er habe die Verführung zur Idolatrie im Sinn gehabt, so wie es für Orvieto und viele andere Orte offenkundig ist. Und um sich bei den Einwohnern von Orvieto für die Aufstellung seiner Statuen über den Toren - wie man sagt - erkenntlich zu zeigen, schenkte er ebendiesen Einwohnern von Orvieto das gesamte Land des Val del Lago, das der Kirche gehörte, ein belastender Skandal zum Nachteil der Kirche und aller Gläubigen der Kirche aus den eigenen Reihen und gegen den Widerspruch aller Vertreter der Gemeinden und Burgen des besagten Landes.

[46] Ebenso wird bewiesen werden, daß ebendieser Bonifaz häufig sagte: ,Das Papsttum ist eine Frucht, die nicht jeder Vogel kennt, aber ich kenne sie gut, wer auch immer Papst ist, ist Herr der geistlichen und weltlichen Dinge und ist Herr der Welt. In Wahrheit, wer auch immer neu zum Papst gewählt wird, es sollte sogleich eine Statue errichtet werden im Namen dessen, der gewählt worden ist, die von allen Großen und Kleinen verehrt wird und vor der sich alle Herrscher der Welt in voller Demut und Verehrung neigen.

[47] Es steht aber fest, daß die vorgenannten Taten des Verdachts auf das verabscheuungswürdige Laster der Idolatrie nicht entbehren und die Tat ist verdammt worden: [Es folgen Hinweise auf 18 Bibelstellen.] Nicht nämlich darf man ein Idol sehen im (Hause) Jakobs, und kein Abbild in Israel, das heißt in der Kirche Gottes. [... $]^{\text {“18 }}$

17 Ebd., 247-357, 249-250, mit der Datierung 1306.

18 Ebd., 277-281: „[43] Octavus articulus est. Item ut suam damnatissimam memoriam perpetuam constituat, fecit imagnies suas argenteas erigi in ecclesiis, per hoc homines ad idolatrandum inducens."

[44] Huius articuli veritas ex ipsa oculorum inspectione probabitur. 
In der dritten, anonymen, vermutlich 1309 entstandenen Fassung ${ }^{19}$ sind die in der Anklageschrift des Pietro Colonna noch additiv nebeneinandergestellten französischen und italienischen Informationen in einem Satz miteinander verknüpft, wobei die Marmorstatuen sogar vor denjenigen aus Metall genannt werden. Der dritte Anklagepunkt, das Dictum des Papstes über einen päpstlichen Bildkult, ist inhaltlich modifiziert, um den Tatbestand der Anstiftung zur Idolatrie in aller Deutlichkeit zum Ausdruck zu bringen. Während in der zweiten Fassung dieses Anklagepunktes nur von demütigen Verbeugungen vor der Statue die Rede ist, heißt es nun, jedermann solle in aller Demut niederknien, betend und sich verbeugend:

„Ebenso, daß er Menschen dazu brachte, seine Bildnisse bald aus Marmor, bald aus Metall an heiligen und öffentlichen Orten zu errichten, und dadurch das Volk Gottes zur Idolatrie verführte, wie ein Ungläubiger, der übel darüber denkt, so wie es offenkundig in Orvieto der Fall ist und an vielen anderen Orten. Den Einwohnern von Orvieto, die an den einzelnen Toren sein Standbild aufstellten, zeigte er sich erkenntlich, indem er ihnen das ganze Gebiet des Val del Lago schenkte, wodurch ebendiese Orvietaner die Römische Kirche beraubt hatten.

Ebenso, daß ebendieser Bonifazius häufig sagte: ,Das Papsttum ist eine Frucht, die nicht alle kennen. Es selbst ist der Herr aller geistlichen und weltlichen Dinge. In Wahrheit, wann auch immer ein Papst gewählt wird, müßte eine Statue errichtet werden, die alle Christen, groß und klein, anbeten und daß alle Herrscher der Welt sie verehren und sich ihr neigen, indem sie in aller Demut und Ehrerbietung die Knie

[45] Item probabitur manifeste quod non solum in ecclesiis, sed etiam extra ecclesias, quod magis ad inducendum idolatriam eum habuisse animum suspicionem inducit, in portis civitatum et super eas, ubi antiquitus consueverunt idola esse, suas imagines marmoreas erigi fecit, sicut patet in civitate Urbevetana et aliis locis pluribus. Et ad remunerandum dictos Urbevetanos de erectione statuarum suarum super portas, ut dictum est dedit eidem Urbevetanis totam terram Vallislacus que erat Camere Ecclesie, in preiudicium Ecclesie et cunctorum fidelium Ecclesie de ipsius partibus scandalum et gravamen, contradicentibus omnibus syndicis communitatum et castrorum dicte terre.

[46] Item probabitur quod idem Bonifacius frequenter dixit: ,Papatus est unum pomum quod non cognoscit omnis avis, sed ego bene cognosco: quicumque est papa, est dominus omnium spiritualium et temporalium et est dominus mundi. In veritate, quicunque papa creatur de novo, statim deberet erigi statua nomine illius qui creatus est, quam omnes magni et parvi reverentur et cui omnes mundi principes, cum omni humilitate et reverentia inclinarent.'

[47] Constat autem quod supradicti actus vitii abominabilis idolatrie suspicione non carent et factum est damnatus Apoc., 13; Matth., 24; Marci, 14; Macab., 1, cap. 1; Zacarie, 9; Abacuc, II, in fine; Amos, 7; Osee, 12 in principio; Daniel, 14 et cap. 3; Ezechiel, 8; Ierem. super Baruc, cap. ult.; Ierem., 45; Isa., 44; Paralip., 3,34; Regum, 4 cap. 23; Deuter. 4. „Non enim debet videri in Iacob, nec simulacrum in Israel, id est Ecclesia Dei, Num., 23.“

19 Ebd., 399-438. 
beugen.' Dies hätte niemals ein Katholik, der nicht Häretiker ist, denken und dem Menschen nach Höherem drängend das zuschreiben können, was allein Gottes ist." 20

Clemens Sommer hat in seiner 1920 erschienenen und ausschließlich der Idolatrie-Anklage gegen Bonifaz VIII. gewidmeten Dissertation die generellen Thesen dargelegt, die man in der späteren Forschung immer wieder findet: Er betonte, daß es sich um einen politischen Prozeß handelte, in dem viele Tatsachen willkürlich manipuliert wurden. Der „Vorwurf der Idolatrie“ bzw. der „Verleitung zur Idolatrie" habe wie andere Anschuldigungen in erster Linie als Vorwand gedient. Der „eigentliche Kernpunkt“ der Anklage sei „die Auffassung des Papstes von seiner unbeschränkten Oberherrschaft in geistlichen und weltlichen Dingen “ gewesen. Dies zeige insbesondere der „angebliche Ausspruch Bonifaz VIII.“, daß jedem neu gewählten Papst eine von allen Christen zu verehrende Statue zu errichten sei. ${ }^{21}$ Die Anklage ließe insbesondere Erinnerungen an römische Kaiserstatuen und deren Ablehnung durch die frühen Christen erkennen. Was Sommer als sicher bezeugt ansah, reichte seiner Auffassung nach aber dazu aus, ein Konfliktpotential zu diagnostizieren. Bonifaz sei mit seiner im Kern bereits neuzeitlichen „Neigung, sein Bild der Nachwelt überliefert zu sehen“22 zwangsläufig mit traditionellen, auf dem Dekalog fußenden Vorbehalten gegen Bildnisse in Widerspruch geraten. ${ }^{23}$ Dies allein hätte ,ihm schwerlich zum Verbrechen ausgedeutet werden können“. Aber durch sein ,ins Übermaß gesteigerte Machtbewußtsein“24 und „sein schroffes bis zum Äußersten rücksichtsloses Wesen“ habe er sich ein „Heer von Feinden“ geschaffen (die Colonna, Philipp den Schönen und seine Anhänger, die Papst Cölestin V. nahestehenden Spiritualen des Franziskanerordens), bei denen nahezu jede gegen ihn vorgebrachte Anschuldigung Rückhalt finden konnte. ${ }^{25}$

20 Ebd., 419-420: „Item quod homines inducebat ad imaginem suam tam ex marmoribus, quam ex metallis erigendam, etiam in locis sacris et publicis, per hoc populum Dei ad idolatrandum inducens, tanquam infidelis et male de hoc sentiens, ut patet in Urbeveteri et in multis aliis locis. Quos Urbevetanos in singulis portis ponentes statuam suam, ex hoc remuneravit, donans eis totam terram Vallislacus, quo Romanam Ecclesiam iidem Urbevetani spoliaverant.

Item quod idem Bonifacius frequenter dicebat: ,papatus est unum pomum, quod non cognoscunt omnes. Ipse est dominus omnium spiritualium et temporalium. In veritate, quandocunque creatur papa, deberet erigi una statua, quam omnes christiani, magni et parvi, adorarent, et quod omnes mundi principes, cum omni humilitate et reverentia genua flecterent, adorantes et inclinantes.' Quod nunquam catholicus non hereticus sentire potuisset, ascribere nitens homini que sunt solius Dei.“

21 Sommer 1920 (wie Anm. 3), 6.

22 Ebd., 32.

23 Ebd., 6-9, 33.

24 Ebd., 8.

25 Ebd., 33. 
Das außerordentliche Machtbewußtsein des Papstes, das ihm zu Lebzeiten nicht nur erbitterte Feinde attestierten ${ }^{26}$, und die große Zahl seiner Bildnisse führten zu der Annahme, er habe durch direkte oder indirekte Einflußnahme kommunale Gremien dazu veranlaßt, ihn durch Statuen zu ehren. ${ }^{27}$ Aufmerksamkeit fand dabei auch der ihm angelastete Ausspruch, jedem Papst sollte zu Beginn seines Pontifikats eine von jedermann zu verehrende Statue errichtet werden. Die Frage nach der Authentizität des Gesagten wurde wiederholt positiv beantwortet. So stellte bereits Werner Hager fest, die Sache passe "ganz und gar zu der Gesinnung des Papstes, wie sie sonst überliefert und belegt ist. ${ }^{2{ }^{28}}$ Vorsichtiger, wenn auch inhaltlich entsprechend urteilte Gerhart Ladner. Der Ausspruch besitze eine "persönliche Färbung“ aufgrund derer es "nicht unwahrscheinlich" sei, daß er tatsächlich auf Bonifaz zurückgehe. Ladner vertrat zudem ausdrücklich die Meinung, daß die Anklage auch in diesem Punkt willkürlich sei: Der Ausspruch bedeute „natürlich nicht Aufforderung zum Götzendienst.“ „Verherrlichende Erinnerung an den Papst als den Stellvertreter Gottes auf Erden“ sei „vielmehr der Sinn der Statuen, die sich Bonifaz zu Lebzeiten errichten ließ.“ Eine solche Ehrung habe „ohne Zweifel mehr der höchsten Würde, die der Papst verkörperte, als seiner Person" gegolten. ${ }^{29}$ Jean Coste und Agostino Paravicini Bagliani stuften den Ausspruch ebenfalls nicht als Unterstellung ein. ${ }^{30}$ Bonifaz habe wohl gewußt, daß antiken Kaisern Bildnisse geschaffen wurden, die an wichtige Orte des Reiches versandt wurden. ${ }^{31}$ Tilmann Schmidt setzte aus rechtshistorischer Sicht andere Akzente. In seinem Aufsatz Bonifaz VIII. und die Idolatrie vertrat er die Auffassung, die Frage nach der "Faktizität“ sei überbewertet worden. Es käme in diesem Fall gar nicht so sehr darauf an zu wissen, „wie es wirklich gewesen ist“. Die publica vox et fama habe, von entsprechenden Leuten bezeugt, „zum Beweis einer Klagebehauptung vollgültig beitragen [können]“. Es sei unter den philosophisch-juristisch Gebildeten der Zeit eine weit verbreitete Praxis gewesen, kaum nachweisbare Vorwürfe in Anklageschriften zu verwenden, welche eher zum Zwecke propagandistischer Diffamierung denn als sachliche Grundlage rechtsförmiger Akkusation dienen konn-

26 Maria Consiglia De Matteis: La memoria di Bonifacio VIII, in: Bonifacio VIII, Atti del XXXIX Convegno 2003 (wie Anm. 2), 520-539.

27 Keller 1939 (wie Anm. 2), 283; Ladner 1970 (wie Anm. 2), Bd. 2, 320; Gardner 1983 (wie Anm. 2), 514 und 516; Tilmann Schmidt, in: Lexikon des Mittelalters, Bd. 2 (1999), Sp. 414-416, 415, s. v. Bonifaz VIII.

28 Hager 1929 (wie Anm. 2), 10.

29 Ladner 1970 (wie Anm. 2), Bd. 2, 299.

30 Coste 1995 (wie Anm. 7), 280 mit Anm.1: „Idée non attestée par ailleurs. L'allusion aux statues des Caesares est ici plus que probable. Ce fantasme romain pourrait bien remonter à l'accusé et non à l'accusateur.“

31 Paravicini Bagliani 2003 (wie Anm. 2), 334-335. 
ten. ${ }^{32}$ Die Relevanz der Vorwürfe beurteilte Schmidt unterschiedlich. Brisant erschienen ihm allein die Silberstatuen: „Denn die genannten Ehrenstatuen waren weder aus Silber noch waren sie dazu bestimmt, in Kirchen aufgestellt zu werden, das heißt also: an Stellen, vor denen das Volk sich zu Gottesdienst und Andacht zu versammeln pflegte, wodurch zu allererst die Rede von der Anbetung einer Papststatue und somit von Idolatrie hätte aufkommen können." 33 „Idolatrie als Verehrung und Anbetung des Abbildes eines in diesem Fall noch lebenden Menschen in der Kirche, eben Bonifaz VIII.“ sei „qualitativ etwas anderes als die Präsentation von Standbildern an öffentlichen Plätzen unter freiem Himmel“. Der ursprünglich strafrechtlich relevante, „präzise Begriff der Idolatrie“ sei „zum Zweck der Einbeziehung der italienischen, außerkirchlichen Ehrenstatuen in der zweiten Fassung der Articulatio ausgeweitet (worden) bis zum Verlust jeglicher Konturen [...].“34 Bei seiner Auffassung des „präzisen Begriff[s] der Idolatrie“, den er seinen Beurteilungen der strafrechtlichen Relevanz der überlieferten idolatrischen Tatbestände und Vorwürfe zugrunde legt, kann sich Schmidt nicht auf rechtshistorische oder sonstige Quellen stützen. Er nimmt an, daß eine Statue nur dann im strafrechtlichen Sinne als idolatrisches Kultbild interpretiert werden konnte, wenn die „topographische Situation“ eines Sakralraums vorhanden war. ${ }^{35}$

Die Brisanz der verschiedenen Bildnisse bleibt nach wie vor unklar. Kann man Schmidts Meinung, die von derjenigen des Verfassers der zweiten Anklageschrift abweicht, zustimmen, daß die Silberfiguren tatsächlich mit idolatriekritischen Vorbehalten wesentlich stärker belastbar waren als die Marmorbildnisse? Warum sollte die auf öffentlichen Plätzen unter freiem Himmel vor Standbildern vollzogene Verehrung und Anbetung eines Menschen juristisch belanglos sein? Wenn man mit den Vorwürfen primär propagandistische Ziele verfolgte, wenn es darum ging, den Papst zu diffamieren, welches Publikum hatte man im Auge? Wen glaubte man mit den nach Schmidts Interpretation strafrechtlich eher konturlosen Anklagepunkten überzeugen zu können? Da in Italien kommunale Gremien Ehrenstatuen für Herrscher, Päpste und verdienstvolle politische und militärische Amtsträger unbedenklich fanden und auch in Frankreich Herrscherstatuen gebilligt wurden, konnte man dann überhaupt noch mit einer nennenswerten idolatriekritischen Sensibilität rechnen? Kann man die Idee einer von allen Menschen kniefällig zu verehrenden und anzube-

32 Schmidt 1986 (wie Anm. 4), 76; vgl. auch Heike Johanna Mierau: Gerüchte als Medium der Grenzüberschreitung - der Prozeß gegen Papst Bonifaz VIII., in: Tagungsband zum 11. Symposion des Mediävistenverbandes 2005 (im Druck).

33 Schmidt 1986 (wie Anm. 4), 78; ähnliche Bewertungen der französischen Papststatuetten äußerten auch Butzek 1978 (wie Anm. 2), 63 und Gardner 1983 (wie Anm. 2), 515 und 520.

34 Schmidt 1986 (wie Anm. 4), 79.

35 Ebd., 82. 
tenden Papststatue tatsächlich Bonifaz zutrauen? Ist sie das Produkt auf die Spitze getriebener Vorstellungen der suprema potestas des Papstes oder wurde diesem das Ganze nur in propagandistischer Absicht von seinen Anklägern unterstellt?

Zunächst fallen bei einer erneuten Lektüre der Anklageschriften zwei Punkte auf. 1. Die immer wieder angenommenen „Erinnerungen an antike Kaiserstatuen" (Sommer) sind quellenkritisch nicht präzise greifbar. 2. Nur in dem dritten Anklagepunkt wird behauptet, Bonifaz habe offen einen Bildkult gefordert.

In der ersten Version der Idolatrie-Anklage wird die eigentliche Zweckbestimmung der in Kirchen aufgestellten Statuen verschwiegen. Aber es wird Bonifaz nicht wie später unterstellt, er habe offen Formen der Verehrung gefordert, die dem christlichen Gott vorbehalten sind („que sunt solius Dei“). ${ }^{36}$ Es wird noch nicht einmal ihre Aufstellung auf dem Hauptaltar der jeweiligen Kirche als belastend erwähnt. Um dem Idolatrievorwurf Substanz zu verschaffen, wird allein behauptet, Bonifaz habe sie zur Erinnerung an seine Person aufstellen lassen. Dabei wird mit allem Nachdruck betont, daß er eine solche dauerhafte Ehrung beanspruchte, obwohl er sie nicht verdient habe. Die Erinnerung an seine Person sei verdammungswürdig. Der damit gegebene Hinweis auf die Schlechtigkeit des Papstes ist wichtig. Er konnte durchaus als hinreichende Begründung aufgefaßt werden, um die Aufstellungen seiner Bildnisse als offensichtliche Versuche der Idolatrieanstiftung zu denunzieren. Als Grundlage diente die traditionelle Vorstellung, der zufolge Bildnisse frevelhafter Herrscher seit jeher eine Hauptursache idolatrischer Irrtümer bildeten und deshalb als Idole abgelehnt werden müssen. Negative Eigenschaften, die nicht ohne weiteres strafrechtlich verwertbar waren ${ }^{37}$, konnten in Verbindung mit Bildnissen, für die dasselbe galt, zu einem kriminellen, den rechten Glauben gefährdenden Tatbestand verknüpft werden. Das liegt auf der Hauptlinie des Prozeßkonzepts, nämlich daß Bonifaz in umfassender Weise als manifester Ketzer („hereticus manifestus ${ }^{\text {“38) }}$ zu gelten habe.

Auch in Verbindung mit den Papststatuen der italienischen Kommunen ist von Kaiserstatuen des antiken Rom, päpstlichen Machtansprüchen und offener Aufforderung zur Idolatrie nicht die Rede. Es heißt lediglich, man finde die Bildnisse des Papstes dort, wo einst Idole standen: „in portis civitatum et super

$36 \mathrm{Zu}$ der erst in der dritten Version vorhandenen formelhaften Formulierung vgl. Isidor von Sevilla, Etymologiarum sive originum libri XX (Ed. W. E. Lindsay 1911), Lib. VIII, 11, 11-12: „Idolatria idolorum servitus sive cultura interpretatur. Nam $\lambda \alpha \tau \rho \varepsilon \_\alpha$ Graece, Latine servitus dicitur, quae quantum ad veram religionem adtinet, nonnisi uni et soli Deo debetur. Hanc sicut inpia superbia sive hominum sive daemonum sibi exhiberi vel iubet vel cupit, ita pia humilitas vel hominum vel angelorum sanctorum sibi oblatam recusat, et cui debetur ostendit."

37 Vgl. Schmidt 1989 (wie Anm. 7), 273.

38 Coste 1995 (wie Anm. 7), 116. 
eas, ubi antiquitus consueverunt idola esse.“ Der topographische Hinweis dient in erster Linie dazu, von vornherein auszuschließen, daß mit den Bildnissen positive religiöse Absichten verfolgt worden sein könnten. Bezeichnenderweise wird ausdrücklich betont, daß die profanen Aufstellungsorte in höherem Maß als sakrale die Absicht der Anstiftung zur Idolatrie deutlich werden ließen. ${ }^{39}$ Der Ankläger versucht vorrangig, anhand äußerer Indizien evident erscheinen $\mathrm{zu}$ lassen, was entgegen seiner mehrfach wiederholten Beteuerungen nicht unmittelbar offen lag, nämlich die verwerflichen Motive des Papstes. Das zeigt auch die Behandlung des Beispiels Orvieto. Es werden Begleitumstände in den Vordergrund gerückt, die keineswegs direkt mit Idolatrie zusammenhängen, die jedoch so präsentiert werden, daß sie den behaupteten idolatrischen Absichten Evidenz verleihen. Um zu zeigen, wie wichtig Bonifaz seine Bildnisse nahm, wird die Feststellung, er habe der Kommune von Orvieto kirchliche Besitztümer überlassen, um die Unterstellung erweitert, er habe dabei beabsichtigt, die Orvietaner für die ihm errichten Statuen zu belohnen. Seine idolatrische Gesinnung sei also so stark gewesen, daß er sich dazu habe hinreißen lassen, der Kirche auch materiellen Schaden zuzufügen. ${ }^{40}$

Allein der dritte Anklagepunkt, Bonifaz habe sich für einen päpstlichen Bildkult ausgesprochen, der alle Menschen und vor allem alle Fürsten zur demütigen und demonstrativen Anerkennung päpstlicher Machtvollkommenheit verpflichten sollte, läßt idolatrisches Konfliktpotential deutlich erkennen, und hier ist auch der „eigentliche Kernpunkt ${ }^{\text {"41 }}$ der politischen Auseinandersetzung zwischen Philipp dem Schönen und Bonifaz virulent: der päpstliche Anspruch auf die plenitudo potestatis, die Überordnung der geistlichen über die weltliche Gewalt. Wichtig ist, daß in diesem Zusammenhang nicht von vielen, sondern nur von der Aufstellung einer einzigen Statue die Rede ist. Wichtig ist dies insbesondere zur Bestimmung der bisher nicht beachteten Inspirationsquelle dieses Vorwurfs. Die Idee eines auf eine einzige Statue zentrierten Bildkults, der dazu dient, die Macht eines Weltreiches zu verherrlichen, entstammt dem Alten Testament, dem Buch Daniel 2,3. In diesem wird im dritten Kapitel berichtet, der babylonische König Nebukadnezar habe eine solche Statue errichten lassen:

39 Außer den beiden Bonifaz-Statuen in Orvieto wurde nur diejenige in Bologna an einem profanen Bau installiert. Die anderen fünf großfigurigen Bildnisse erhielten einen Aufstellungsort an und in Kirchen.

40 Den Anklägern war nicht bekannt, daß die für die Kommune von Orvieto günstigen Vereinbarungen den für Bonifaz dekretierten Statuen vorausgingen. Der Papst hatte auf eigennützige Weise familiäre Interessen verfolgt. Vgl. Heinrich Finke: Aus den Tagen Bonifaz VIII. Funde und Forschungen, Münster 1902, 236; Peter Herde: Das Kardinalskollegium und der Feldzug von Orvieto im Val del Lage (1294), in: Erwin Gatz (Hrsg.), Römische Kurie. Kirchliche Finanzen. Vatikanisches Archiv. Studien zu Ehren von Hermann Hoberg, Rom 1979, Bd. 1, 325-275, bes. 333 -335, 354-356; Coste 1995 (wie Anm. 7), 278 mit Anm. 3 und 279 mit Anm. 1-2.

41 Sommer 1920 (wie Anm. 3), 6. 
„Der König Nebukadnezar ließ ein goldenes [Stand] Bild machen, sechzig Ellen hoch und sechs Ellen breit, und ließ es setzen ins Tal Dura in der Landschaft Babel. Und der König Nebukadnezar sandte nach den Fürsten, Herren, Landpflegern, Richtern, Vögten, Räten, Amtsleuten und allen Gewaltigen im Lande, daß sie zusammenkommen sollten, das Bild zu weihen, das der König Nebukadnezar hatte setzen lassen. Da kamen zusammen die Fürsten, Heeren, Landpfleger, Richter, Vögte, Räte, Amtleute und alle Gewaltigen im Lande, das Bild zu weihen, das der König Nebukadnezar hatte setzten lassen. Und sie mußten dem Bilde gegenübertreten, das Nebukadnezar hatte setzen lassen. Und der Herold rief überlaut: Das laßt euch gesagt sein, ihr Völker, Leute und Zungen! Wenn ihr hören werdet den Schall der Posaunen, Trompeten, Harfen, Geigen, Psalter, Lauten und allerlei Saitenspiel, so sollt ihr niederfallen und das goldene Bild anbeten, das der König Nebukadnezar hat setzen lassen." ${ }^{\text {"2 }}$

Die sich anschließende Schilderung der drei jungen Männer im Feuerofen, die sich weigerten, die Statue anzubeten, war als biblisches Exemplum der Ablehnung heidnischen Herrscherkult geläufig. Ihre Äußerung gegenüber Nebukadnezar - „[du sollst wissen], daß wir deine Götter nicht ehren noch das goldene Bild, das du hast setzen lassen, anbeten wollen" - nahm Hieronymus zum Anlaß für eine kritische Stellungnahme gegen den römischen Kaiserkult:

„Du sollst wissen König, daß wir deine Götter nicht verehren, und die goldene Statue, die du errichtet hast, nicht anbeten. Ob wir Statue lesen möchten wie Symmachus oder goldenes Abbild, wie die übrigen übersetzt haben, die Diener des Herren dürfen es nicht anbeten. Also sollen weltliche Richter und Herrscher, die die Statuen und Abbilder der Kaiser anbeten, verstehen, daß sie das tun, was die drei Jünglinge zu tun verweigerten und so Gott gefielen. Zu tadeln sei die Eigenart, Götter zu verehren oder ein Abbild anzubeten, sagen sie, weil beides Dienern Gottes nicht zukomme." ${ }^{\text {"43 }}$

42 Die Bibel oder die ganze Heilige Schrift des Alten und Neuen Testaments nach der deutschen Übersetzung von Martin Luther, Textfassung 1912, Stuttgart 1985.

43 Hieronymus, Commentaria in Danielem, PL 25, 507: „Notum tibi sit, rex, quia deos tuos non colimus, et statuam auream quam erexisti, non adoramus. Sive statuam, ut Symmachus, sive imaginem auream, ut caeteri transtulerunt, voluerimus legere, cultores Dei eam adorare non debent. Ergo judices et principes [0507D] saeculi, qui imperatorum statuas adorant, et imagines, hoc se facere intelligant, quod tres pueri facere nolentes placuerunt Deo. Et notanda proprietas, deos coli, imaginem adorari dicunt, quod utrumque servis Dei non convenit." - Zur spezifischen Position des Hieronymus in der Haltung der Kirchenväter zur Kaiserbildpraxis vgl. Horst Bredekamp: Kunst als Medium sozialer Konflikte. Bilderkämpfe von der Spätantike bis zur Hussitenrevolution, Frankfurt a. M. 1975, 25. 
Abb. 2-4: Fragmente einer antiken kolossalen Bronzestatue, Rom, Kapitolinische Museen

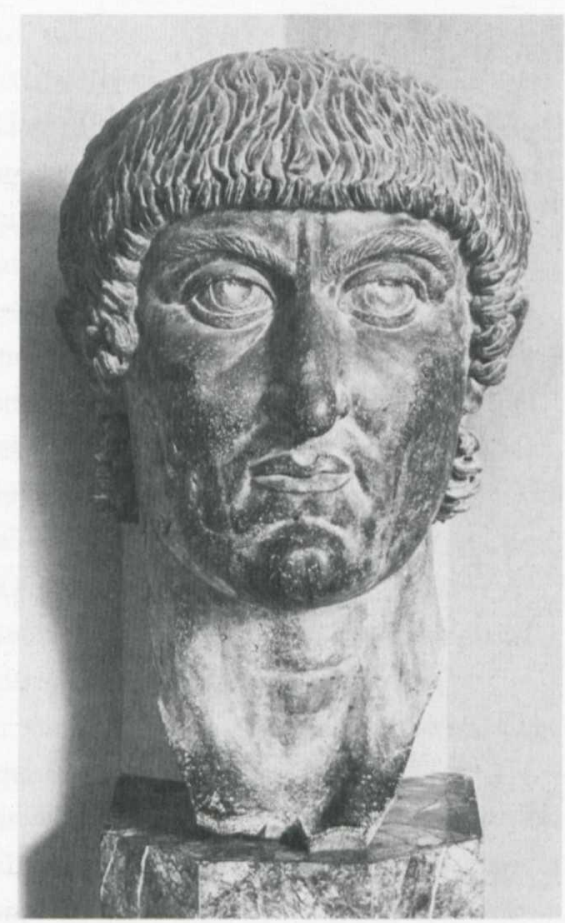

Eine mittelalterliche Adaption der alttestamentlichen Überlieferung der Nebukadnezar-Statue hatte direkt vor der Haustür des päpstlichen Palastes von Bonifaz VIII. ihren Ursprung: Mittelalterliche Rombesucher konnten vor dem Lateranspalast zwei antike Bronzen bestaunen, die hier möglicherweise bereits in karolingischer Zeit aufgestellt worden waren. ${ }^{44} \mathrm{Zu}$ diesen gehörten als besonders spektakuläre Mirabilien der sogenannte equus Constantini (die Reiterstatue des Marc Aurel) und der Kopf eines Bronzekolosses sowie die zu diesem gehörende Hand mit Globus (Abb. 2, 3 und 4). Die beiden Bildwerke evozierten das heidnische und das christliche Rom, indem sie an Beispiele vorbildlicher christlicher und negativer heidnischer Herrschaft erinnerten. Zugleich verdeutlichten sie exemplarisch legitimen und illegitimen Gebrauch statuarischer Monumente. Die Reiterstatue diente der Memoria des ersten christlichen Kaisers und verwies auf das Constitutum Constantini; die Fragmente des Bronzekolosses erinnerten an das vorkonstantinische heidnische Imperium Romanum und dessen

44 Ingo Herklotz: Der Campus lateranensis im Mittelalter, in: Römisches Jahrbuch für Kunstgeschichte 22, 1985, 1-43; ders.: Gli eredi di Costantino. Il papato, il Laterano e la propaganda visiva nel XII secolo, Rom 2000, 75-87. 

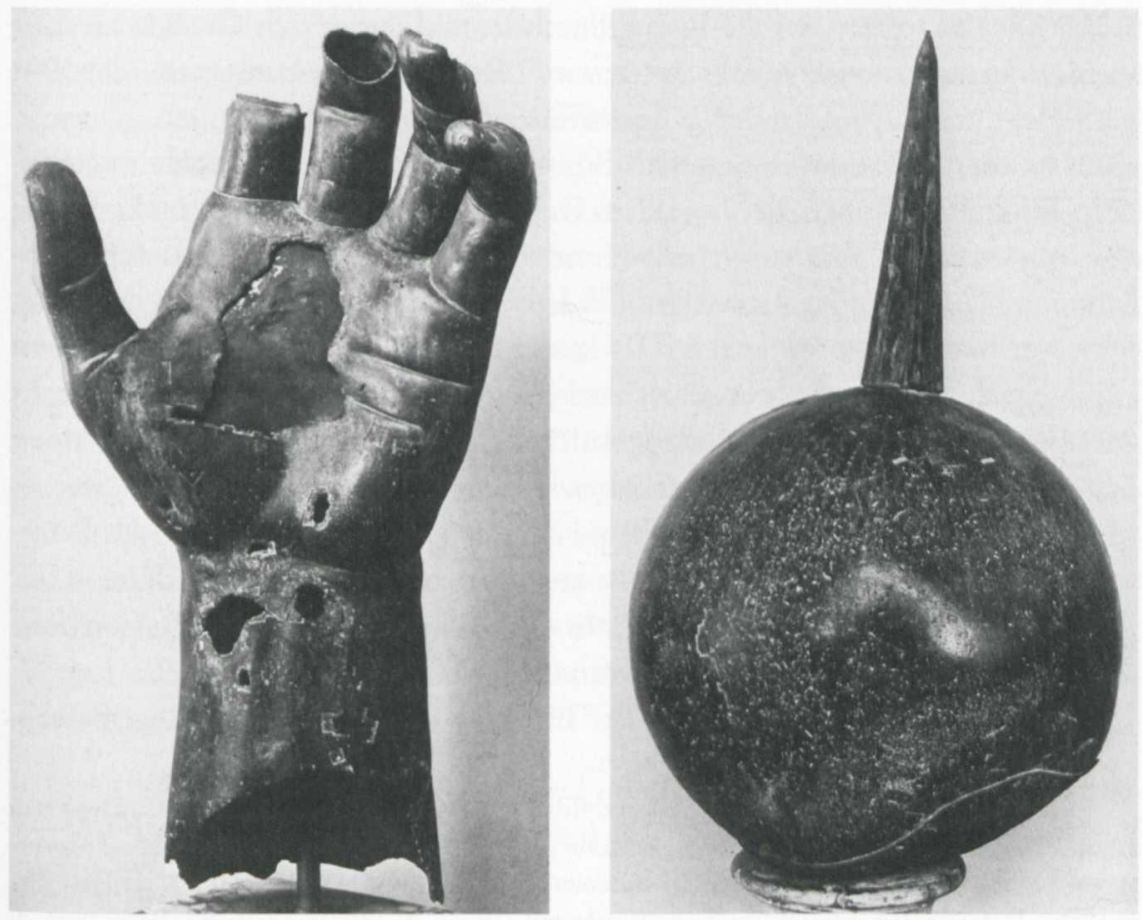

Untergang. Man assoziierte den Kopf und die zu diesem gehörende Hand mit dem von Nero in der Nähe des Kolosseums errichteten und von Vespasian nachträglich veränderten colossus und glaubte daher in erster Linie, daß man es mit einem Sonnenidol zu tun habe. Von Gelehrten, die mit der in den Universalchroniken tradierten Lehre der vier aufeinanderfolgenden Weltreiche vertraut waren, wurde das Bildwerk aber auch in geschichtstypologischer Analogie zu Nebukadnezars idolatristischem Herrscherkult gesehen und als Götze römischer Weltherrschaft gedeutet. Beide Auffassungen sind bereits im frühen 13. Jahrhundert in der Rombeschreibung des englischen Magisters Gregorius greifbar. Er berichtet nicht nur, daß die Statue ursprünglich das Dach des als Tempel des Sol fungierenden Kolosseums bekrönte und sich Tag und Nacht auf dem Bauwerk, dem Lauf der Sonne folgend, drehte, sondern erwähnt in Zusammenhang mit der ihr zugeschriebenen heidnischen Kultfunktion ebenso die auch in stadtrömischen Mirabilien-Texten bezeugte alternative Überlieferung, der zufolge es sich um eine Darstellung der Roma (effigies Romae) handele. Der Globus in der Rechten bedeute die von Rom beherrschte Welt, ein ehemals in der Linken gehaltenes Schwert die virtus bellica. Zur Blütezeit des römischen Weltreichs hätten alle Besucher Roms die Statue mit gebeugten Knien verehrt und damit der Stadt gehuldigt. Später, in christlicher Zeit, als man die heidni- 
schen Götzen stürzte, sei die Statue durch Papst Gregor den Großen zerstört worden. In stadtrömischen Varianten wird diese Tat in die konstantinische Zeit vorverlegt und Papst Silvester zugeschrieben. ${ }^{45}$

Man kann nicht annehmen, daß Bonifaz sich wiederholt für einen päpstlichen Bildkult aussprach, der bei jedem Gebildeten die Erinnerung an die Statue des babylonischen Königs Nebukadnezar wachrufen mußte und der für Romkenner zudem mit dem Bronzeidol des Lateranplatzes assoziiert war, das Papst Sylvester hatte zerstören lassen. Das in der Anklageschrift enthaltene Dictum eignete sich bestens, um vor allem auch Klerikern überzeugend den Verdacht darzulegen, daß Bonifaz mit seiner Auffassung der ihm als Papst zustehenden Ehrbezeugungen sich auf idolatrischen Abwegen befand. Vermutlich war es nicht nur durch das Alte Testament und die mittelalterliche Deutung des Bronzekolosses angeregt worden, sondern auch durch ein ehemals im Bereich der Benediktionsloggia des Lateranspalastes vorhandenes Wandbild. ${ }^{46}$ Dessen politische Ikonographie verdeutlichte Grundgedanken der päpstlichen plenitudo potestatis, so wie sie Bonifaz 1302 in der Bulle Unam Sanctam dargelegt hatte ${ }^{47}$,

45 Magister Gregorius: Narracio de mirabilibus urbis Romae, hrsg. v. R. B. C. Huygens, Leiden 1970, 16-18; Jacobus ab Aquis, Chronicon, imaginis mundi, Historiae Patriae Monumenta Scriptorum, Tomus III, Turin 1848, 1624; Nicolás Rosell: De Mirabilibus civitatis Romae, in: Roberto Valentini/Giuseppe Zucchetti (Hrsg.), Codice topografico della città di Roma, 4 Bde., Rom 1940-53, Bd. 3, 195-196.

46 Charles Mitchell: The Lateran Fresco of Bonifaz VIII, in: Journal of the Warburg and Courtauld Institutes 14, 1951, 1-6; Lajos Vayer: L'affresco del giubileo e la tradizione della pittura monumentale romana, in: Giotto e il suo tempo, Atti del congresso internazionale per la celebrazione del VII centenario della nascità di Giotto, 14 settembre - 1 ottobre 1967, Assisi - Padova - Firenze, Rom 1971, 45-59; Silvia Maddalo: Bonifacio VIII e Jacopo Stefaneschi. Ipotesi di lettura dell'affresco della loggia lateranense, in: Studi Romani 31, 1983, 129-150; Herwarth Röttgen: Die Inbesitznahme des Lateran durch Bonifaz VIII. Überlegungen zur Wirklichkeit der Benediktionskanzel in Giottos Fresko und zur alten Benediktionskanzel des Lateran, in: Martin Kintzinger (Hrsg.), Das Andere Wahrnehmen. Beiträge zur europäischen Geschichte, Köln 1991, 141-168; Silvia Maddalo: Ancora sulla loggia di Bonifacio VIII al Laterano. Una proposta di riscostruzione e un'ipotesi attributiva, in: Arte medievale Ser. II, 12-13, 1998-1999, 211-230; Francesco Gandolfo: Bonifacio VIII, il giubileo del 1300 e la loggia delle benedizioni al Laterano, in: Mario D’Onofrio (Hrsg.), Romei e Giubileo. Il pellegrinaggio medievale a San Pietro (350-1350), Milano 1999, 219-228; Gary Dickson: The Crowd at the Feet of Pope Boniface VIII: Pilgrimage, Crusade and the First Roman Jubilee (1300), in: Journal of Medieval History 25, 1999, 279-307; Agostino Paravicini Bagliani: Bonifacio VIII, l'affresco di Giotto e i processi contro i nemici della chiesa. Postilla al Giubileo del 1300, in: Mèlanges de l'École Française de Rome/Moyen âge 112/1, 2000, 459-485.

47 Walter Ullmann: Die Bulle Unam Sanctam. Rückblick und Ausblick, in: Römische Historische Mitteilungen 16, 1974, 45-77; Tilmann Schmidt: Papst Bonifaz VIII. als Gesetzgeber, in: Proceedings of the 8th International Congress of Medieval Canon Law (San Diego 1988), Città del Vaticano 1992, 227-245; Paravicini Bagliani 2003 (wie Anm. 2), 303-310; Emanuele Conte: La bolla Unam Sanctam e i fondamenti del potere papale fra diritto e teologia, in: Bonifacio VIII, i Caetani e la storia del Lazio, Atti del Convegno di studi storici, Roma, Latina, Sermoneta, 30 novembre - 2 dicembre 2000, Rom 2004, 43-61. 
daß nämlich jeder Mensch heilsnotwendig dem im geistlichen und weltlichen Bereich dominierenden Papst Gehorsam schulde („Porro subesse Romano Pontifici omni humanae creaturae declaramus, dicimus, diffinimus esse de necessitate salutis"). ${ }^{48}$ Eine aus dem 16. Jahrhundert stammende kleinformatige Kopie zeigt den Papst umgeben von Klerikern in erhöhter Position auf einer Baldachinarchitektur (Abb. 5). ${ }^{49}$ Unter ihm war der ihm huldigende populus christianus zu sehen, der das niedrige Volk ebenso umfaßte wie kommunale Amtsträger, Ritter, Adelige und Fürsten.

Das Standbild Nebukadnezars war in vielfacher Weise als Prototyp illegitimen, idolatrischen Herrscherkults im Mittelalter geläufig, und es wurde wie bereits von Hieronymus zur Fundierung kritischer Stellungnahmen zu zeitgenössischen Idolen herangezogen. Einen interessanten Beleg hierfür liefert Pierre Bersuire in seinem Repertorium morale. In seinen Ausführungen zu dem Stichwort Idolum vertritt er gestützt auf eine Auslegung von Daniel 3,1-3, die Verherrlichung hochmütiger Herrscher und sonstiger Würdenträger sei bereits eine Art von Idolatrie:

"Als Idol wird jenes Bild, jene Figur oder Statue oder jenes Abbild bezeichnet, das von alters her von den Ungläubigen als Gott verehrt wurde [...] Zunächst also sage ich, das Idol bezeichne die hochmütig Erhobenen und die Ehrgeizigen. So wie nämlich ein Idol, obwohl ohne Wirkmacht und Sinn, dennoch von alters her auf einen hohen Platz gestellt, wie Gott angebetet, öffentlich mit Weihrauch geehrt und durch verschiedene Kulthandlungen und Opfer von den Ungläubigen verehrt wurde [...] so aber sind es heute die Ehrgeizigen, die, obwohl sie jeden Sinns und Verstands, jeder Tugend und Scheu, jeder Wirkung und jeder guten Handlung entbehren, selbst heute in hohen Würden und Ämter überhöht werden, wo auch immer herausragende Menschen für vollkommene Götter gehalten werden, wo immer sie auch von Ungläubigen, d.h. den Bewunderern, verehrt und geehrt werden, und wo auch immer sie durch die Verehrung und die Zurschaustellung beweihräuchert und angespornt werden. Diese werden in jenem Idol präfiguriert, das heißt in jener Statue, die der König Nebukadnezar errichten ließ [...] So also sehen wir [...], daß heute viele Idole, das heißt viele unnütze und dumme Personen vom König Nebukadnezar, d.h. vom Papst, vom König oder Kaiser in hohe Würden, Ämter, Praelaturen und Pfründe erhoben werden. “50

48 Bonifaz VIII., Bulle Unam Sanctam (1302), URL: <http://theol.uibk.ac.at/leseraum/texte/250-31.html> (25.07.2006).

49 Giacomo Grimaldi: Instrumenta translationum, Mailand, Biblioteca Ambrosiana, MS. F inf. 227, fol. 8v-9r; Kat. Anno 1300 il primo Giubileo 2000 (wie Anm. 2), 170-171, Nr. 116 (Silvia Maddalo).

50 Petrus Berchorius: Opera omnia sive reductorium, repertorium et dictionarium morale utriusque testamenti, Tomus tertius, Coloniae Agrippine 1692, 359-360: „Idolum. Nota quod 
Pierre Bersuires Idol- bzw. Idolatriebegriff ist von radikaler Bilderfeindlichkeit weit entfernt. Es dient vor allem als kritische Waffe zur Denunzierung der Verehrung und Zurschaustellung hochmütiger Inhaber geistlicher oder weltlicher Ämter. Idolatrisches Fehlverhalten ist nach seinen Ausführungen eine generelle Angelegenheit der Verehrung von Personen, die in sozial gehobener Stellung den Anforderungen christlicher Moral nicht gerecht werden. Bildnisse können, müssen aber nicht involviert sein.

Pietro Colonna hat in seiner Anklageschrift die gegen Bonifaz erhobenen Vorwürfe der Anstiftung zur Idolatrie mit einer Auflistung von 18 Verweisen auf Bibelstellen untermauert, die bisher nicht kommentiert wurden. Sie betreffen 18 Bücher des Alten und Neuen Testaments. Welche Stellen gemeint sind, ist nicht immer ganz eindeutig, da in fast allen Fällen nur die Kapitel angegeben sind und nur zweimal durch die Hinweise ,in fine“ bzw. „in principio“ die Abschnitte näher bezeichnet sind. Beim Nachlesen der einzelnen Bücher und Kapitel stellt man fest, daß Pietro Colonna die Bibel von hinten nach vorne durchging. Dabei hat er keineswegs alle Stellen zum Idolatrie-Problem erfaßt. Inhaltliche Auswahlkriterien und Schwerpunkte sind nicht zu erkennen. Man findet überwiegend Äußerungen gegen heidnische Götterbilder, die nicht direkt auf die Bonifaz-Bildnisse übertragbar waren (Num. 23,21; Dt. 4,15-19; IV Reg. 23,4-25; II Par. 34,3-7; Is. 44,9-20; Ier. 44,17-25; Bar. 6,3-72; Ez. 8,10-18; Dan. 14,1-21; Os. 12,8; Am. 7,9; Hab. 2,18-20; Zac. 9,7). Eine generelle Bilderfeindlichkeit (,alte auf dem Dekalog fußende Vorurteile“51) kann man der Anklage dennoch nicht attestieren. Das Bilderverbot des Dekalogs (Ex 20,4) und analoge Bibelstellen (Lv 26,2; Dt 4, 16-18; Dt 5,6-8) sind nicht berücksichtigt. Da Erläuterungen fehlen, läßt sich zumeist nur vermuten, welche Argumente man mit ihnen verband. Einige Beispiele betreffen Gottesstrafen für die Anhänger heidnischer Kulte (Dt. 4; Ier. 44; Bar. 6,1-3; Os. 12,3; Am. 7). Die Erwähnung von Gold und Silber als Materialien, aus denen Götzen geschaffen wurden (Bar. 6,3-72; Hab. 2,19), ließ sich zur Kritik der aus diesen Metallen

idolum est illa imago, figura, statua, seu similitudo, quae antiquitus ab infidelibus pro Deo colebatur [...] Primo igitur dico, quod Idolum signat superbos elatos, et ambitiosos. Sicut enim idolum quamuis esset sine virtute, et sine sensu, tamen antiquitus in alto loco ponebatur, tanquam Deus adorabatur, coram ipso thurificabatur, et diuersis cultibus et muneribus ab infidelibus colebatur [...] sic vere hodie sunt ambitiosi qui quamvis careant omni sensu et ratione, omni virtute et discretione, omni motu et bona operatione, ipsi tamen hodie in altis dignitatibus et officiis sublimatur, ubi dii, id est viri excellentes, et perfecti esse creduntur, ubi etiam ab infidelibus, id est ab adulatoris coluntur, et honorantur, et ubi per adulationem, \& vanae laudis exhibitionem thurificantur, \& incensantur. Isti figurantur in illo idolo, id est in illa statua, quam fecit erigi Nabuchodonosor rex [...] Sic vere charissimi videmus, quod hodie multa idola, id est multae personae inutiles, et ignorantes a Rege Nabuchodonosor, id est a papa, rege vel imperatore in altis dignitatibus, officiis, praelaturis et beneficiis eriguntur [...].“

51 Sommer 1920 (wie Anm. 3), 6. 

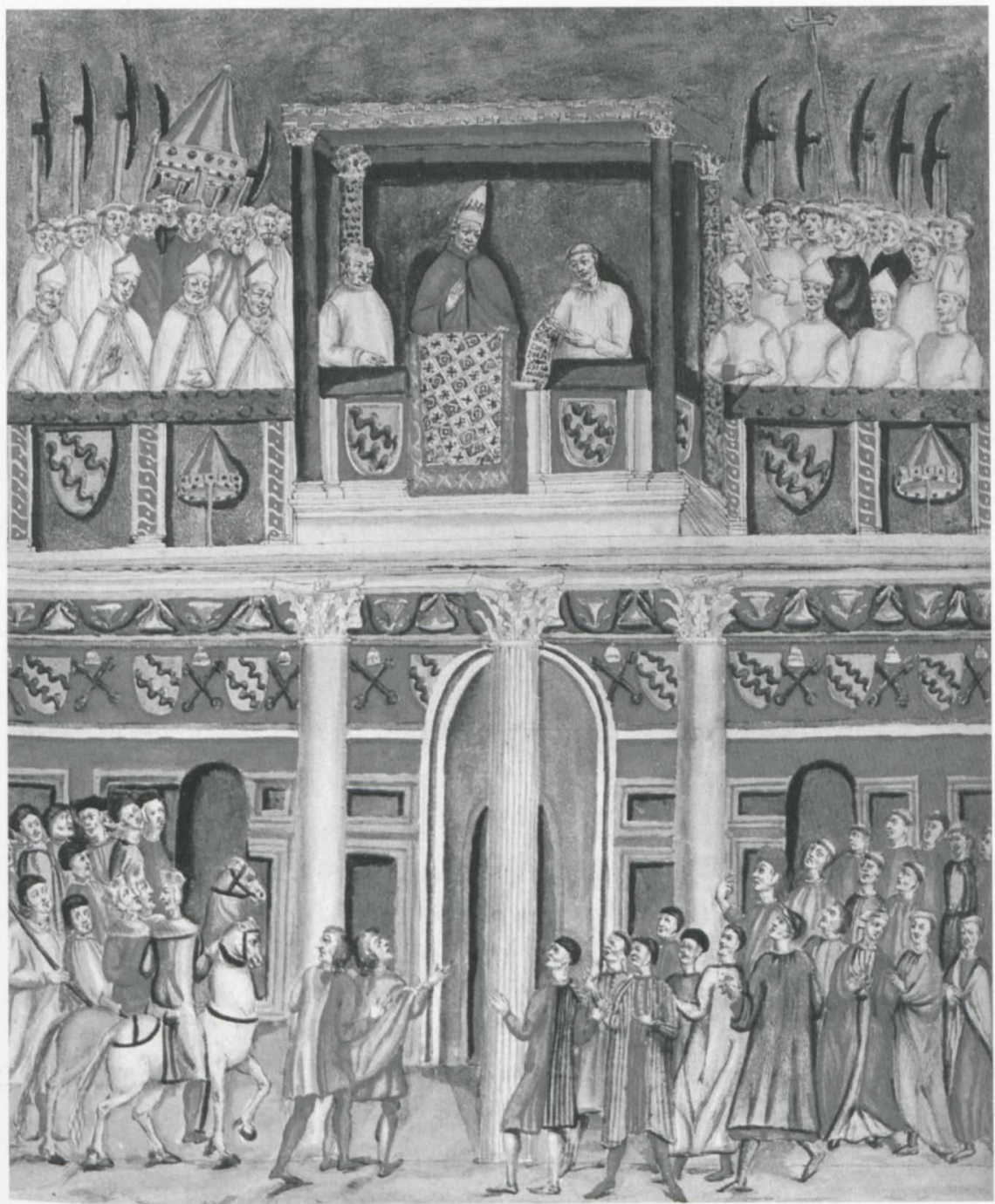

Abb. 5: Bonifaz VIII. in der Benediktionsloggia, Kopie des Freskos in der Lateransloggia, in: Giacomo Grimaldi, Instrumenta translationum, Ende des 16. Jhs., Mailand, Biblioteca Ambrosiana, Ms. F. inf. 227, fol. 3 
hergestellten Statuetten in Reims und Amiens heranziehen. Da es sich nur um zwei Stellen handelt, kann dies jedoch kein vorrangiges Anliegen gewesen sein.

Die Statue des Nebukadnezar (Dan 3,1-30; Apo 13,8.15) ist das einzige Beispiel eines durch einen Herrscher etablierten und zur Demonstration politischer Macht genutzten Bildkults. Eine große Auswahl hatte der Verfasser der Anklage freilich nicht, da Herrscherstatuen in der Bibel eine geringe Rolle spielen. Er hätte jedoch auch das Buch der Weisheit (14, 12-21) hinzuziehen können, in dem in Verbindung mit euhemeristischen Auffassungen die Entstehung von Idolatrie unter anderem anhand der Aufstellung von an anderen Orten residierenden Königen verdeutlicht wird. Das Thema herrscherlicher Idolatrieanstiftung ist allerdings auch noch mit drei weiteren in der Liste erfaßten Bibelstellen (Mat. 24,15-16; Marc. 13,14; I Mac 1,54) eng verknüpft. Deutlich wird dies aber erst, wenn man exegetische Texte berücksichtigt. Die beiden fast gleichlautenden Stellen bei Matthäus und Markus betreffen die zur Wiederkunftsrede Jesu gehörende Vorhersage des „an heiligem Ort stehenden unheilvollen Greuels“. Die Textstelle im Matthäus-Evangelium (24,15-16) lautet:

„Wenn ihr dann den unheilvollen Greuel (abominatio desolationis), der durch den Propheten Daniel vorhergesagt worden ist, an heiligem Ort (in loco sancto) stehen seht - der Leser begreife - dann sollen die Bewohner von Judäa in die Berge fliehen."

Bei Daniel (Dan 9, 27; 11,31; 12,11) weist der Ausdruck abominatio desolationis auf ein (168 v. Chr.) vermutlich von Antiochus Epiphanes im Tempel von Jerusalem aufgestelltes Götzenbild hin. Dieses wird mit demselben Ausdruck auch im ersten Makkabäerbuch erwähnt (1 Mac. 1,54). Der Apostel Paulus bezog im zweiten Brief an die Thessaloniker (2 Thess. 2,3-4) die Vorhersage des Daniel auf den kommenden Antichrist, was später wiederum für die Auslegung der Verse 13-15 im 13. Kapitel der Offenbarung herangezogen wurde. In Anlehnung an diese exegetische Überlieferung hatte Guillaume de Nogaret in einer bereits im März 1303 vor dem königlichen Rat gehaltenen Rede Bonifaz als den von Daniel vorhergesagten Greuel bezeichnet, gegen den man mit Waffen und Gesetzen vorgehen müsse („est enim in peccatis nephantis inveteratus, omnibus viis et doctrinis Domini contrarius et repugnans, templi vera abominatio quam Daniel, Domini propheta describit: et ideo contra eum arma et leges debent insurgere [... ").$^{52}$ Die alttestamentliche Vorhersage wurde jedoch bereits in der Spätantike auch auf den zeitgenössischen herrscherlichen Bildkult bezogen. Hieronymus berücksichtigt in seinem Kommentar zum Matthäus-Evangelium bei der Deutung von Vers 24,15 römische Kaiserbildnisse. Er verweist nicht nur auf die Überlieferung der zufolge Pilatus ein Tiberiusbildnis im Tempel von 
Jerusalem aufzustellen versuchte, sondern erwähnt auch die Reiterstatue Kaiser Hadrians, die noch in seiner Zeit "an diesem allerheiligsten Ort" zu sehen war. ${ }^{53}$ Die Ausführungen des Kirchenvaters wurden von mittelalterlichen Theologen aufmerksam zur Kenntnis genommen und gelegentlich auch erweitert. So werden zum Beispiel in der Historica Scholastica des Petrus Comestor und im Speculum Historiale des Vincenz von Beauvais zusätzlich Statuen des Gaius Caligula erwähnt, die ebenfalls im Tempel von Jerusalem standen. ${ }^{54}$ Beachtung verdient hier auch der dem Johanniterorden angehörende Theologe Jean de Hesdin, der Ende der 60er Jahre des 14. Jahrhunderts in einem Brief an Petrarca die in Mailand in San Giovanni in Conca hinter dem Hauptaltar stehende Reiterstatue des Signoren Bernabò Visconti in Anlehnung an Matthäus 24,15 und Hieronymus als „abhominabile idolum super altare Dei“ auffaßt und als Akt herrscherlichen Hochmuts verurteilt, der die Strafe Gottes nach sich ziehen werde. ${ }^{55}$

Vor dem Hintergrund der von mittelalterlichen Autoren vertretenen Auffassungen von Idolatrie werden die Konturen der von Guillaume de Plaisians und Pietro Colonna formulierten Idolatrieanklagepunkte deutlich. Es handelt sich um durchaus schlagkräftige Vorwürfe, die bei gebildeten Klerikern Beachtung fanden. Obwohl man es mit den Fakten nicht sehr genau nahm und aus vagen Anhaltspunkten fürchterliche häretische, simonistische und sodomitische crimi$n a$ konstruierte, behauptete man nicht, Bonifaz habe offen und unmißverständlich verlangt, als Gott verehrt zu werden. Vielmehr unterstellte man ihm, er habe Bildnisse und Ehrenerweisungen ausschließlich zur Befriedigung seines Hochmuts eingesetzt. Maßlose herrscherliche Geltungssucht galt seit jeher in der christlichen Tradition als Hauptursache idolatrischer Vergehen und diese Auffassung hatte nach wie vor Anhänger. Dabei hat man nicht nur an extrem konservative Hüter christlicher Orthodoxie oder weltabgewandte Bettelmönche zu denken, sondern gerade auch an humanistisch gesinnte Gelehrte. Die willkürliche Manipulation und partielle Erfindung der Tatbestände zeigt ferner ebenso deutlich, daß Bonifaz das Maß der ihm als Papst geschuldeten Ehrenerweisungen keineswegs so radikal und offensichtlich mißachtet hatte, wie man ihm in diffamierender Absicht unterstellte. Als päpstlicher Mäzen bewegte er sich auch dort, wo er neue Wege ging und die päpstliche Ikonographie durch programmatische Neuerungen bereicherte, innerhalb der Bahnen dessen, was Theologen an Ehrenrechten für das Papsttum reklamierten. Aber er hatte auch

53 Hieronymus, Commentariorum in Matheum, CCSL, 225.

54 Petrus Comestor: Historia Scholastica, PL 198, Sp. 1610 Cap. CXXXVIII; Vincenz von Beauvais: Speculum Historiale, Lib. X, Cap. 90 (Ed. Graz 1965, 400).

55 Enrico Cocchia: Magistri Iohannes de Hysdinio invectiva contra Fr. Petrarcham et Fr. Petrarchae contra cuiusdam galli calumnias apologia. Revisione critica del testo con introduzione storica e commento, in: Atti della R. Accademia di Archeologia, Lettere e Belle Arti di Napoli 7, 1919, 93-201, 124. 
auf massive Weise Signale visueller Selbstdarstellung eingesetzt, die nicht seine päpstliche persona publica betrafen und somit den Vorwürfen seiner Gegner Plausibilität verliehen. Wie kein Papst vor ihm hat sich Bonifaz durch den vielfältigen Einsatz seines Familienwappens als persona singularis aus dem Geschlecht der Caetani in der Öffentlichkeit präsentiert. ${ }^{56}$ Hierfür gab es keine theologische Rechtfertigung.

Bildnacbweis: Abb. 1: Joachim Poeschke: Die Skulptur des Mittelalters in Italien. Gotik, München 2000, Taf. 86; Abb. 2-4: Herklotz 1985 (wie Anm. 44), 30 u. 31; Abb. 5: Silvia Maddalo: Roma miniata, Roma affrescata. Tracce di un mito fra Trecento e Quattrocento, in: Gloria Fossi (Hrsg.), La Storia dei Giubilei, Bd. 1, Rom 1997, 118.

$56 \mathrm{Zu}$ den ,armorial achievements“ Bonifaz' VIII. siehe Donald Lindsay Galbreath: Papal Heraldry (1930), second edition revised by Geoffrey Briggs, London 1972, vgl. auch Keller 1939 (wie Anm. 2), 292-293; Paravicini Bagliani 2003 (wie Anm. 2), 289; zu Bonifaz' Verfolgung familiärer Eigeninteressen siehe Paravicini Bagliani 2003 (wie Anm. 2), 287-290, 323, 350, 366; Anna Esposito: La famiglia Caetani, in: Bonifacio VIII, Atti del XXXIX Convegno 2003 (wie Anm. 2), 67-88. Als Oberhaupt der Caetani präsentiert sich Bonifaz VIII. auch dadurch, daß er 1296 seinen Neffen Benedetto Caetani, den Kardinaldiakon von SS. Cosma e Damiano vor dem Altar im Boden der Kapelle beisetzen ließ3. Garms/Sommerlechner/Telesko 1994 (wie Anm. 6), 140. Interessant ist auch hier wieder der gehäufte Einsatz des Familienwappens am Sarkophag. 